\title{
Affecting Factors and Security System of Food Production - A Case Study of Mingshan County
}

\author{
Lin Zheng (Corresponding author) \\ College of Economics and Management, Sichuan Agricultural University \\ Wen'jiang 610000, Sichuan, China \\ Tel: 86-189-8162-2640Ｅ-mail: 273432312@qq.com \\ Wenxiu Zhang \\ College of Economics and Management, Sichuan Agricultural University \\ Wen'Jiang 610000, Sichuan, China \\ E-mail: 857539031@qq.com
}

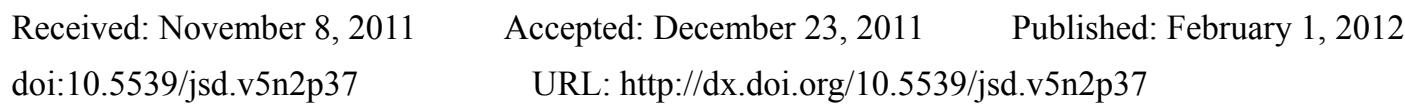

\begin{abstract}
The Grey Relational Analysis of food production has been established based on the data of grain production in Mingshan County, Sichuan province, collected from 2003 to 2008. According to the Relational Grade, factors that affect the County's input on grain production and the degree of their influence have been analyzed. The conclusion is that unit grain yield, sown area of grain, and rural labor force is important factors affecting the county's food production. Thus many advices were proposed, like giving priority to food security, strictly implementing farmland protection system, increasing grain yield through the improvement of per capita output, and improving preferential policies relating to grain production.
\end{abstract}

Keywords: Food production, Grey correlativity analysis (GCA), Food security

\section{Introduction}

Food is the most important stuff, and food price is the basis of any price. Food is taken as a strategic commodity as it largely concerns people's livelihood. Food security is not just an economic but also an important social issue. It is related to the economic development and social stability. Being a developing agricultural county, China has $10 \%$ of the world's arable land, while it has $22 \%$ of the world's population. Billion people's feeding has always been a top priority. China's 2001 white paper on food issue clearly stated that China can supply itself with sufficient food, which is the basic principle for the government to resolve the issue of food security. Attaching great importance to the improvement of comprehensive ability of food production, establishing stable commodity grain bases, setting up food security system according to our situation and the request of socialist market economy, and ensuring the balance of food supply and demand; all these are not only the basic guidance of solving food security problem, but also the overall goal of food security.

Therefore, how to improve food production and ensure food security has been the top concern of the government and the whole society. The third plenum of the 17th Communist Party of China Central Committee clearly pointed out that in 2020 one basic task of China's rural development is to protect national food security. Document No. 2009 of the Central Committee of the Party lists "the issues of agriculture, farmer and rural area" and "national food security" as top priorities. According to the definition of the Food and Agriculture Organization (FAO), food in this paper mainly refers to grain, which includes wheat, coarse grains and rice.

Known as the grain house of Ya'an city, Mingshan county has for years been a major food production county of the city, and also one commodity grain base of the Sichuan province. The stability of Mingshan County's food production (supply) not only directly effect Mingshan County's food security, but also seriously influences that of Ya'an.

Many scholars have conducted numerous studies on the analysis of factors affecting food production. According to the data of food production in Chongqing city during 1990 ton 2007, Yong-jing Qi and Ya-cheng Xiao 
established a linear production function model. Based on the flexibility of influencing factors, they analyzed factors and the degree of influence of Chongqing city's input on food production, and proposed that great importance should be laid on food security in Chongqing (Y. J. Qi \& Y. C. Xiao, 2009). Xiao-song Song and Kai-luo Leng selected food-production-related data of four major grain-producing provinces in China since the reform and opening-up, did regression analysis for the major factors affecting each province's grain production with econometric software, and drew their conclusions (X. S. Song \& K. L. Leng, 2009). Chang-liang Shi, Zhong-ping wang and Hao Zhou, using the grey correlation and Production function, analyzed the data of grain production in Xinjiang from 1980 to 2009, and figured out the influencing factors and their contribution rate (C. L. Shi et al., 2011). Yu-meng Wang analyzed factors that affect the food production of Hubei province, and used the grey prediction model to conduct trend forecast and correlation analysis of the factors. The results dynamically reflected the development trend of food production in Hubei Province, and provided theoretical basis for the sustainable development of food production and scientific decision-making (Y. M. Wang, 2011). Many scholars adopt a method of quantitative analysis to the affecting factors of food production, and they generally choose a large scale to analyze, while small scale less.

The author uses the grey relational analysis method to analyze the data of Mingshan county's food production from 2003 to 2008 and its affecting factors of food production, so as to raise attention to food security and the establishment of food security system. This paper is strived to provide some suggestion to the building of food security system of MingShan County, and set an example for all counties of Ya'an to consider.

\section{Present Condition of Food Production in Mingshan}

\subsection{Grain Acreage is on the Decrease}

With mild climate and abundant rainfall, Mingshan is an idea place for grain cultivation, especially for rice. In recent years, with the adjustment of industrial structure and the implementation of "reconverting cultivated land into forest" policy, Mingshan's crop planting structure has undergone fundamental changes: from sole grain to a combination of grain and tea. And tea acreage is increasing year by year, while that of rice and other grain crop are decreasing. The rice acreage has been reduced by 45\%, from 202000 acres in 2000 to 118000 acres in 2009, leading to an increasingly worse situation of food production.

\subsection{Food Consumption is on the Rise and Imbalance between Supply and Demand is Worsening}

With people's living standards improving, per capita food consumption is decreasing. However, as an agricultural county which breeds pigs and sells them to Daxian county, Mingshan witnesses an increase demand of grains. $85 \%$ rural households have to buy feeding grain, mainly corn. The average purchase of corn for each household is as many as 1624 kilograms. Thus the imbalance between food supply and demand is more and more serious.

\subsection{Grain Reserves has Sharply Declined}

\subsubsection{Rural Grain Reserves Reduced Drastically}

Reduction of grain acreage and total grain output lead to the county's food reserves decreasing sharply. According to statistics, $65 \%$ rural households stored grain which can last till the next harvest and no more left, and $35 \%$ need to purchase grain.

\subsubsection{State-owned Grain Enterprises' Stock Declined to Historical Low Level}

Grain enterprises take major part of Mingshan's grain stock. Since the opening of grain market, the volume of grain purchase of state-owned grain enterprises has been decreasing year by year, the reserve is lessening accordingly. Their grain reserves fell sharply, from 32003 tons in 2000 to 2200 tons in 2008, hitting a historically level. Worse still, Mingshan's grain warehouse facilities are backward. If Mingshan falls behind in the building of warehouse facilities, it will be hard to provide quality storage for the sake of food security.

\subsubsection{Urban Residents Hardly Stock Grain}

As Mingshan is a major grain-producing county, its people tend to believe that there is no short of food, and they do not hold stock. Therefore, they lack capacity of resisting food risks.

\section{Empirical Analysis of Factors Affecting Food Production in Mingshan}

\subsection{Research Methods and Data Sources}

\subsubsection{Grey Relational Analysis}

Degree-correlation is defined as the correlation of degrees in a pair of factors varying with the time. Grey relational analysis is a multivariate statistical analysis method. It is sample-data founded, and uses grey 
degree-correlation to indicate the degree of correlation between factors. If two factors are reflected in the sample data column a basically same tendency (direction, size, speed, etc.), they are closely correlated. Otherwise they are loosely correlated. So the grey relational analysis is based on the degree of similarity or dissimilarity of factors' developing tendency, also known as grey degree-correlation, and is taken as a method to measure correlation degree.

Grey relational analysis steps

(1) Define reference grey numeral sequence and comparative grey numeral sequence. The numeral sequence reflecting the features of system behavior, known as the reference grey numeral sequence. Factors affecting the system behavior form numeral sequence, which is said the comparative grey numeral sequence.

(2) Do the non-dimensional for reference grey numeral sequence and comparative grey numeral sequence.

(3) Find the greay relational coefficient $\xi(\mathrm{Xi})$ about reference grey numeral sequence and comparative grey numeral sequence. The reference grey numeral sequence $\mathrm{X} 0$ has a number of comparative grey numeral sequence $\mathrm{X} 1, \mathrm{X} 2, \ldots, \mathrm{Xn}$, their correlation coefficient $\xi(\mathrm{Xi})$ is calculated at any time by the following formula:

$$
\zeta_{o i}(k)=\frac{\min i \min k\left|x_{o}(k)-x_{i}(k)\right|+\rho \max i \max k\left|x_{o}(k)-x_{i}(k)\right|}{\left|x_{o}(k)-x_{i}(k)\right|+\rho \max i \max k\left|x_{o}(k)-x_{i}(k)\right|}
$$

$0<\zeta<1, \rho \in(0,1)$

(4) Find the relational coefficient ri:

$$
r_{o i}=\frac{1}{n} \sum_{k=1}^{n} \zeta_{o i}(k)
$$

(5) Arrange relational sequence.

\subsubsection{Data Source}

The model takes annual time-series data, with sample period from 2003 to 2008. Data on agricultural machinery power comes from Mingshan Bureau of Agricultural Statistics; rural power consumption from Mingshan Power Authority; the rest from "Sichuan Statistical Yearbook."

\subsection{Grey Dynamic Correlation Analysis and the Results}

\subsubsection{Grey Dynamic Correlation Analysis}

In theory, there are many factors that may affect food production, such as land, labor force, chemical fertilizer, machinery, natural environment, technology, management and policy. The author chose following five variables--sown area of grain, chemical fertilizer input, per capita output, labor force, and disaster area - to analyze their effect on grain production.

(1) Sown area of grain is a key variable to explain the change of grain output; it is a positive effect (Qi \& Xiao, 2009).

(2) Per capita is the biggest effect on grain output; its increase can directly boost grain output. That's why this paper lists it as one factor.

(3) Chemical fertilizer is a major input in the grain production. The data of chemical fertilizer input in this paper is verified quantity, using the same statistic method.

(4) Disaster area can reflect natural disasters' degree of influence, which is a negative one. The statistics on disaster area published are of crops as a whole, without any solely of grain. So the data on disaster area in this paper is from the Bureau of Agricultural.

(5) Labor force is also an important factor. At present, there is no specific official statistics on labor force engaging in grain production. Thus this paper takes rural labor force as index of labor input.

(6) As this paper has listed disaster area as one factor, it would not consider the effect of weather, which is claimed by experts negligible in five years.

For the establishment of model and clarity of analysis, factors affecting Mingshan's food production are highly generalized. For instance, seeds, pesticide, farm machinery and technologies can pose serious effect on unit grain yield. Thus grain yield per acre is taken as representative element of grey correlation analysis. That's how the following elements are chosen to be solely listed for the correlation analysis of input and output. 
Eight main factors that influence Mingshan county's grain output are picked out on the basis of $2003-2008$ numeral sequence data, and by applying the method of grey dynamic correlation analysis to qualitative judgment of the affecting factors and analysis of the current situation of grain production. They are: X1 - the sown area of grain (ha), X2 - grain yield per acre ( $\mathrm{kg} / \mathrm{ha}$ ), X3 -chemical fertilizer input (ton), X4 - food disaster area (ha / ton), X5 - rural labor force (person), X6 -pesticide application (ton), X7 - rural electricity consumption (ten thousand kwh), X8 - total agricultural machinery power (MW). While Y - total grain production (ton) being the explanatory variable, the above variables' year data being the sample, the grey relational analysis generates out dynamic correlation of the eight major affecting factors (Table 1).

\subsubsection{Grey Dynamic Correlation Analysis Results}

Table1 shows the sequence of the eight variables' degree-correlation (R): rural labor force $>$ sown area of grain $>$ grain yield per acre $>$ rural electricity consumption $>$ chemical fertilizer input $>$ disaster area $>$ agricultural machinery power $>$ pesticide application. It indicates that grain yield per acre, sown area of grain and rural labor force are the top three affecting factors, followed by rural electricity consumption, chemical fertilizer input, disaster area, agricultural machinery power, and pesticide application. Bellow is the conclusion generated:

(1) Grain yields per acre, sown area of grain, and rural labor force are important factors affecting food production in Mingshan county. The increase of food production relies on unit grain yield and sown area of grain. However, according to statistics in 2003--2008 period, the aggregate output of grain in Mingshan in recent years is increasing despite the reduction of grain yields per acre. The results of ray correlation analysis suggests an increase of rural labor force, which correspondents to the reality.

(2) In terms of the correlation of input and output, rural labor and rural electricity consumption have the biggest degree-correlation with food production, which indicates that the two input elements are great effect on food production. The degree-correlation of rural labor force in 2008 is 0.996826, ranking first; Since 2003, the degree-correlation between food production and rural labor force has been rising year by year. It reflects the increasing capacity of rural labor force in food production boost. Rural electricity consumption is significantly related with aggregate food production, but their correlation coefficient sees a decrease year after year, from 0.903844 in 2003 to 0.727834 in 2008.

(3) Total agricultural machinery power and pesticide application have weak degree-correlation with grain output, merely 0.7355 and 0.7290 respectively. It indicates that the two factors are not yet major one. The grey relational coefficients of agricultural machinery power is on the whole sliding, from 0.9417 in 2003 to 0.6152 in 2008. The grey relational coefficients of chemical fertilizer input ranks the fifth, and disaster area the sixth, indicating a small influence o the increase of grain output. Pesticide affliction has the weakest degree-correlation, only 0.729 , posing little effect on grain boost.

\section{Strategies and Reflection}

Based on the above results of grey relational dynamic analysis, we can propose some strategic advices for Mingshan's food production. The fundamental one is the establishment of food security system. Food security is a systematical complex, which carries through links of production, storage and circulation. All these links are inter-related to form a complex system called food safety guarantee system. And food safety guarantee in production, storage and circulation consist of basic contents of food security system.

\subsection{Production Guarantee}

\subsubsection{Stabilizing Sown Area of Grain and Increasing Unit Grain Yield}

According to the results of grey dynamic analysis, Mingshan's food production relies mainly on the increase of agricultural labor force, sown area of grain and unit grain yield. However, in the course of economic development, the extensive economy that is powered by land capitalization should be replaced by an intensive one that is featured with land saving and agricultural industrialization. Further efforts should be laid on the protection of basic farmland and the stabilization of sown area. During this process of land consolidation, we can actively spread advanced planting technology, and vigorously develop quality grain, so as to increase unit grain yield and grain production income.

\subsubsection{Further Improving Preferential Policies on Food Production}

Preferential policies are a boost of farmers' enthusiasm in grain planting. It also helps in the quick reverse of the low grain price and the forming of a stable and reasonable grain price mechanism.

\subsection{Reserve Guarantee}

According to the results of grey dynamic analysis, disaster area also has some impact on the total grain output. 
Therefore, it is necessary to further perfect the grain reserve system. Considering the basic situation of food production in Mingshan, to establish an efficient and flexible food reserve system is a main means for the government to balance grain supply and demand and even out price fluctuation, and also a request for food security.

\subsection{Circulation Guarantee}

\subsubsection{Perfecting Early-Warning Mechanism of Food Security, Ensuring Grain Safety in an Emergency}

According to the results of grey relational analysis, food disaster area has a certain impact on the total grain output. So it is necessary to establish and perfect an early-warning mechanism of food security. The food safety emergency system is a process that, through early warning, prevention and processing, aims to avoid crisis or reduce its damage, and to discover opportunities out of crisis. Food security is ever dynamically changing. Fluctuation in food production happens frequently. Public emergency is difficult to predict. The Wenchuang gave us alarm about the importance of ensuring food guarantee in emergency, which requires an early-warning system and emergency processing net featured with timeliness, swiftness, and effectiveness. It means that the grain bureau not only needs a contingent of talented workers, but also advanced techniques in information collecting, emergency processing and distribution, and storage technology. To make food safety emergency system keep up with the changing situation, the government should constantly increase investment in technology, so as to sure emergency measures work in critical time to secure food safety in Mingshan.

Food security system is a complex system; any link during production, reserve and circulation can not go wrong. With the growing population, accelerating process of urbanization, and the change of food demand structure caused by higher living standard of people, China's grain demand will keep a tendency of rigid growth. As a result, the pressure of grain supply will be ever greater in the future. Many factors can influence food production; many problems need to be solved. But food security is a omnipotent cure that plays a key role in stable grain production. Therefore, the realization of food security is a long-term difficult task. Unremitting efforts on food security is one of our basic national policies, and also a requirement of building a wholesome food security system.

\section{References}

Si, C. L., Wang, Z. P., \& Zhou, H. (2011). From 1980 to 2009 analysis the main factors associated with grain production in Xinjiang. Agricultural Research in Arid region, 5.

Yu, F. W. (2005). Analysis factors influence grain production and suggest policy. Agricultural Systems Science\& Comprehensive research, 2, 133-135.

Xiong, H., Tan, L. Y., \& Wang, Z. Y. (2006). Analysis factors affecting grain production in Nanning City. Journal of Huazhong Agricultural University (Social Sciences Edition), 6, 46-50.

Xiao, H. F., \& Wang, J. (2004). Factors influencing China's grain production capacity. Agricultural technology economy, 6, 45-49.

Yi, P., \& Duan, Y. C. (2008). Dynamic analysis the factors influencing production of our country grain. Rural economy, 1, 53-57.

Yu, Q. Y., Wu, W. B., Tang, H. J., Chen, Q. Y., \& Yang, P. (2011). A Food Security Assessment in APEC Based on Grain Productivity: Scientia Agricultura Sinica, 44, 2838-2848. http://dx.doi.org/10.3864/2.901164

Song, X. S., \& Leng, K. L. (2009). Comparative analysis factors influencing food production in China's major grain-producing provinces. Journal of Yunnan Finance\& Economics Universit, 23, 108-110.

Bian, Y. J., \& Xiao, Y. C. (2009). Analysis the factors influencing grain production in Chongqing City. Journal of Southwest Agricultural University ( Social Sciences Edition), 10, 30-33.

Wang, Y. M. (2011). Grey dynamic analysis of food production in Hubei Province. Agricultural technology economy, 6 . 
Table 1. Mingshan total grain production factors grey correlation coefficient

\begin{tabular}{|c|c|c|c|c|c|c|c|c|}
\hline & 2003 & 2004 & 2005 & 2006 & 2007 & 2008 & coefficient & $\begin{array}{c}\text { Correlation } \\
\text { sequence }\end{array}$ \\
\hline $\mathrm{X} 1$ & 1 & 0.9994 & 0.9169 & 0.9671 & 0.9847 & 0.9707 & 0.9731 & 2 \\
\hline $\mathrm{X} 2$ & 1 & 0.9722 & 0.9632 & 0.9648 & 0.9263 & 0.9018 & 0.9547 & 3 \\
\hline $\mathrm{X} 3$ & 1 & 0.7134 & 0.7161 & 0.7861 & 0.8096 & 0.6767 & 0.7836 & 5 \\
\hline $\mathrm{X} 4$ & 1 & 0.8069 & 0.7826 & 0.8648 & 0.8587 & 0.3333 & 0.7744 & 6 \\
\hline $\mathrm{X} 5$ & 1 & 0.9489 & 0.9747 & 0.9921 & 0.9872 & 0.9968 & 0.9833 & 1 \\
\hline $\mathrm{X} 6$ & 1 & 0.9173 & 0.8286 & 0.5348 & 0.5509 & 0.5421 & 0.7289 & 8 \\
\hline $\mathrm{X} 7$ & 1 & 0.9038 & 0.7918 & 0.8251 & 0.7944 & 0.7278 & 0.8405 & 4 \\
\hline $\mathrm{X} 8$ & 1 & 0.9417 & 0.6339 & 0.6063 & 0.6158 & 0.6152 & 0.7355 & 7 \\
\hline
\end{tabular}

X1 - the sown area of grain (ha), X2 - grain yield per acre (kg / ha), X3 -chemical fertilizer input (ton), X4 food disaster area (ha / ton), X5 - rural labor force (person), X6 -pesticide application (ton), X7 - rural electricity consumption (ten thousand kwh), X8 - total agricultural machinery power (MW), $\mathrm{Y}$ - total grain production (ton). 